\title{
Las artistas mujeres en el Perú decimonónico
}

\author{
Nanda Leonardini \\ Departamento Académico de Arte
}

El primer nombre femenino que registra la Historia del Arte Peruano, es el de la limeña Juana Valera, quien durante el siglo XVII pinta bodegones.

En el arte de la centuria decimonónica se sabe que las mujeres practican el dibujo y la pintura, pues dentro de la currícula escolar dicha asignatura está comprendida en casi todos los establecimientos femeninos. Asimismo, cuando los artistas ofrecen sus servicios para dictar clases particulares, en particular aquellos referidos a la primera mitad del siglo, los anuncios se hallan generalmente dirigidos hacia las damas, señalando que pueden concurrir a sus domicilios particulares.

Afortunadamente nib todo es anonimato con respecto a ellas. Por medio de algunas noticias locáles; [es posible reschatarylgunos de sus nombres; así se ha determinado que existen artistas peruanas y extranjeras. De todas ellas ninguna es escultora, y al menos dos son maestras de Dibujo y Pintura: Sabina Meucci y Eduvijis Sánchez. La primera establece su propio colegio en 1843 en el que se imparte Dibujo, Pintura al óleo, acuarela, temple y Miniatura, mientras la segunda dicta clases de Dibujo en el Colegio Peruano de Enseñanza Mutua para $1851^{1}$. Sin lugar a dudas esto es reflejo del positivismo decimonónico que considera a la educación como la carrera idónea para las mujeres pues a través de ella pueden manifestar las dotes femeninas naturales.

1 "Colegio Peruano de Enseñanza Mutua". En El Comercio, Lima, 28 de marzo de 1851, p. 1 . 
Así Sabina y Eduvijes se insertan en el mundo laboral sin olvidar su misión de esposa, madre e hija.

A mediados de 1845 arriba a Lima Clara Filleul, pintora francesa que acompaña a Monvoisin, quien junto a él permanece en esta ciudad hasta 1847. Retratista como su maestro, mientras lo ayuda aprovecha a realizar algunos - óleos como el Retrato de Matilde Codesido de Bello, obra que no está firmada pero que doña Matilde aseguraba a sus hijos que "una ayudante de Monvoisin era la autora de la obra"”.

De las limeñas activas la primera noticia registrada data de 1848 , año en el cual se establece el Gabinete Optico, galería de arte que todas las semanas cambia sus exposiciones con veinte y dos "vistas" diferentes, la mayor parte proveniente de Europa, aunque también exhiben artistas nacionales. En la muestra inaugurada el sábado 5 de agosto, entre las obras hay una

Interesante vista del incendio del Vaticano en el pontificado de León IV, hecha por una señorita Limeña, discípula del Sr. Yañez ${ }^{3}$.

Como se puede observar el breve comentario no estipula el nombre de la autora; es pues el anonimato, en la mayoría de los casos, la característica que envuelve las obras femeninas.

Durante el agasajo questęe haceGal Presidente Echenique en Palacio de Gobierno, en noviembre de 1853., losingitadosatienen la oportunidad de deleitarse con un cuadro de reciente factura; se trata de la Santa Familia. La sorpresa se convierte en estupor cuando los asistentes comprueban que la tela es realizada por la mano femenina de Eduvijis de Corpancho, a quien de inmediato la comparan en calidad y rango con los pinceles de Francisco Laso y Luis Montero. La crítica entusiasmada comenta al día siguiente de la recepción que la obra está

desempeñada con maestría, perfección y delicadesa $[\ldots]$ nos hizo contemplar por largo espacio y con verdadera admiración, esa magnifica joya de las pinturas peruanas, circunstancia que nos

2 James, David, Monvoisin. Buenos Aires, Emecé Editores, 1949, p. 65.

3 "Gabinete". En El Comercio, Lima, 4 de agosto de 1848, p. 1. 
impele á felicitar á la pintora limeña, estimulandola a que no desmaye en ese jenero de estudio en que está llamada á dar gloria á su patria ${ }^{4}$.

Gracias a la exposición organizada por Leonardo Barbieri en agosto de 1860, sus discípulos, entre los que se encuentran varias damas, pueden exhibir algunos de sus estudios. Entre las expositoras están las señoritas Estenós, García y Dupuch quienes en sus telas, a decir del periodista, "manifestaban ventajosas disposiciones".

$\mathrm{Al}$ año siguiente Isabel Larrañaga, discípula del español Gaspar Valls concentra la atención de la prensa local; al referirse a su Virgen del Carmen rodeada de ángeles y nubes, comenta:

Claro oscuro, tintes ropaje, sencillez y bondad, magestad, misericordia; gracia, contornos, resplandores que difunden el pasmo, el entusiasmo y se apodera del espiritu una conmision divina [...] Loor inmarcesible á la habil señorita que tanto ejemplo da de aprovechamiento y habilidad ${ }^{6}$.

El periodista aprovecha su artículo para reclamar al Gobierno y exigirle, una vez más, que proteja e impulse a la juventud reflejada en la señorita Larrañaga, a fin de difundir éärteca de Letras

\section{"Jorge Puccinelli Converso»}

Sin embargo algunas mujeres persisten en no firmar sus obras; esto se percibe cuando la revista El Perú Ilustrado señala:

En la misma página del anterior grabado se hallan un tipo limeño y otro de caballo, en 1740 , tipos que el lápiz de una señorita ha copiado, espresamente para este número de las obras de Don Antonio Ulloa?.

4 'Peruanos. Artista Peruana". En El Comercio, Lima, 18 de noviembre de 1853, p. 3.

5 "La Exposición de Pintura”. En El Comercio, Lima, 21 de agosto de 1860, p. 2, edición de la tarde. p. 2.

- "La justicia social". En El Comercio, Lima, 21 de agosto de 1861, p. 3.

7 "Nuestros Grabados". En El Perú Ilustrado № 36, Lima, 14 de enero de 1888, p. 2. 
Los grabados a los que se refieren se encuentran en la página $13 \mathrm{sin}$ firma, bajo el título de Español en el traje del Perú-1740 y Vendedor de ramitos de flores. En esta revista es muy usual encontrar litografías carentes de firma, lo que hace presumible que pudieran ser obras de alguna dama.

El año de 1891 reserva algunas sorpresas femeninas. En el mes de febrero se publica la breve noticia que la señorita Casaretti realiza hermosísimos paisajes sobre conchas de mar, expuestos en las vidrieras de la imprenta del semanario El Perú Ilustrado. Para el mes de mayo, en algunos salones de la Biblioteca Nacional, se lleva a efecto una gran exposición-concurso, convocado desde París por la filántropa peruana Adelina Concha de Concha. Además de los once artistas reconocidos en el ámbito, se presentan treinta y nueve participantes; estos tienen como condicionante no ser extranjeros ni ser consagrados. Once son mujeres 8 , y a pesar del reglamento, una de ellas es italiana. Se trata de Emma Codda que había lleggado al país a la edad de cinco años.

Sobre este asunto el crítico Emilio, Gutiêrrez comenta indignado, a favor de la señorita:

He oído hablar de una señorita Emma Codda, á quien por cierto á causa de este accidente se le desconoce (por fuera) el derecho de disfrutar los premios del concurso. Creo que en esta opinión habrá más de envidiaby bajezacquede jusfidia,asíen verdad esta señorita, aunque nacidaıneItalia cśa domícilió ensBerú antes de cumplir sus cinco años, esto es, cuando el nativo clima aun no pudo formar su tipo físico; cuanto menos nacionalizar su fisonomía moral y apropiarse de su talento?.

Una vez superado el incidente Emma Codda presenta tres obras: $L a$ mujer de Sprecia oyendo la proclamación de Moro, Una cara de niño y La Venta del título (copia de Ignacio Merino) con las que se hace acreedora a una medalla de oro. Por su parte la peruana Estela Gómez Carrillo exhibe Un Joven, y Aurora San Cristóval, de la que no se especifica cuál es su trabajo; ambas obtienen medalla de plata.

8 "La fiesta del arte". En El Perú Ilustrado No 209, Lima, 9 de mayo de 1891, p. 2087.

9 Gutiérrez de Quintanilla, Emilio. “Concurso de bellas artes.”. En El Perú Ilustrado N N2 208, Lima, 2 de mayo de 1891, p. 2017. 
Clorinda Corpancho participa con tres motivos peruanos: La flor de la puna, Fortaleza de Saccaihuaman y Nevado del Ausangati, además de un San Francisco de Asís y dos paisajes al pastel; por la calidad de estos recibe una mención honrosa. A Clotilde Rosas se le da un premio extraordinario "por sus delicadas labores de porcelana". Otras señoritas que exponen son: I. Solf, $U n$ retrato y un Cuadro de comedor; Segovia, Un pájaro y una Virgen; Carrillo, Un joven; Prince con dos paisajes; Lissón con La Virgen y el Niño; Elsa Lohengrin, los carboncillos Un ángel y Eva ante sus hijos dormidos ${ }^{10}$.

Gracias al mencionado concurso son develados varios nombres, sin embargo el anonimato continúa siendo la característica de las mujeres. Esto se percibe nuevamente cuando en agosto de ese mismo año de 1891, Belisario Garay realiza un retrato de una joven pintora. El semanario El Perú Ilustrado, donde es publicada la litografía, comenta:

El segundo grabado de la presente edición, bello trabajo de Belisario Garay, representa a una señorita limeña aficionada al arte de Merino; nos complace sobre manera engalanar así nuestro semanario, alentando de algún modo á los que siente en el alma el fuego divino del $\operatorname{arte}^{11}$.

$\mathrm{Al}$ año siguiente (1892) la obra de Rebeca Oquendo es conocida en Lima gracias a la Exposición Nacional habida por el IV Centenario del Descubrimiento de América. NaturaCde Lima, Rebeca Oquendo nace en 1850 en el seno de una familia y participar en la Muestra Internacional de 1878 donde se hace acreedora a una Medalla de Plata. Sus lienzos son eminentemente retratísticos, aunque también ejecuta algunas pinturas de género y de paisaje urbano ${ }^{12}$.

Por su parte Aurora San Cristóval, debido a las enseñanzas de su padre el litógrafo Evaristo San Cristóval, a la edad de once años ya publica sus estudios en el semanario cultural El Perú Ilustrado, revista que abre las puertas a los jóvenes artistas a fin de que estos puedan darse a conocer a la

10 "Concurso artístico". En El Perú Ilustrado N² 208, Lima, 2 de mayo de 1891, p. 2047.

1 "Nuestros Grabados". En El Perú llustrado No 224, Lima, 22 de agosto de 1891, p. 4051.

12 Núñez Ureta, Teodoro. Pintura contemporánea, Primera parte. 1820-1920. Lima, Banco de Crédito del Perú, 1975, p. 114

\section{HEMEROTEGA DE LETRAS}


opinión pública. Cuando su padre edita en 1893 El Perú Artístico, las posibilidades para Aurora se multiplican. Así sus litografías, que versan sobre variados temas como el retrato, el paisaje, las antigüedades prehispánicas, el género, tienen la oportunidad de ser difundidas durante su vida.

De todas estas damas, nada más se ha podido recoger. Hay asimismo otras mujeres que se dedican a bordar cuadros en raso o papel, reproduciendo aldeanas o paisajes, obras a las que no les dan ningún valor pues a veces las rematan para obtener fondos ${ }^{13}$. Para abril de 1887 la señorita Clorinda Corpancho pinta al óleo el escudo nacional en el Pabellón Peruano de la Bomba Lima, labor que le demanda dos meses ${ }^{14}$.

Sin lugar a dudas los nombres y las obras de estas peruanas no son significativas para la sociedad de su época. Si bien es cierto que su presencia es real, está sirve para que, con posterioridad, otras puedan abrirse camino en este ámbito y sus obras fuesen cotizadas.

En una sociedad eminentemente tradicional, donde además resulta difícil vivir de la producción artística, es comprensible que esto suceda, por lo que no resulta extraño que sean pocos los nombres registrados de las mujeres que en este ambiente se atreven a incursionar.

\section{Biblioteca de Letras "Jorge Puccinelli Converso"}

13 "Remate". En El Comercio, Lima, 20 de julio de 1863, edición de la tarde p. 2.

14 "El Pabellón Peruano". En El Comercio, Lima, 29 de abril de 1887, p. 2. 


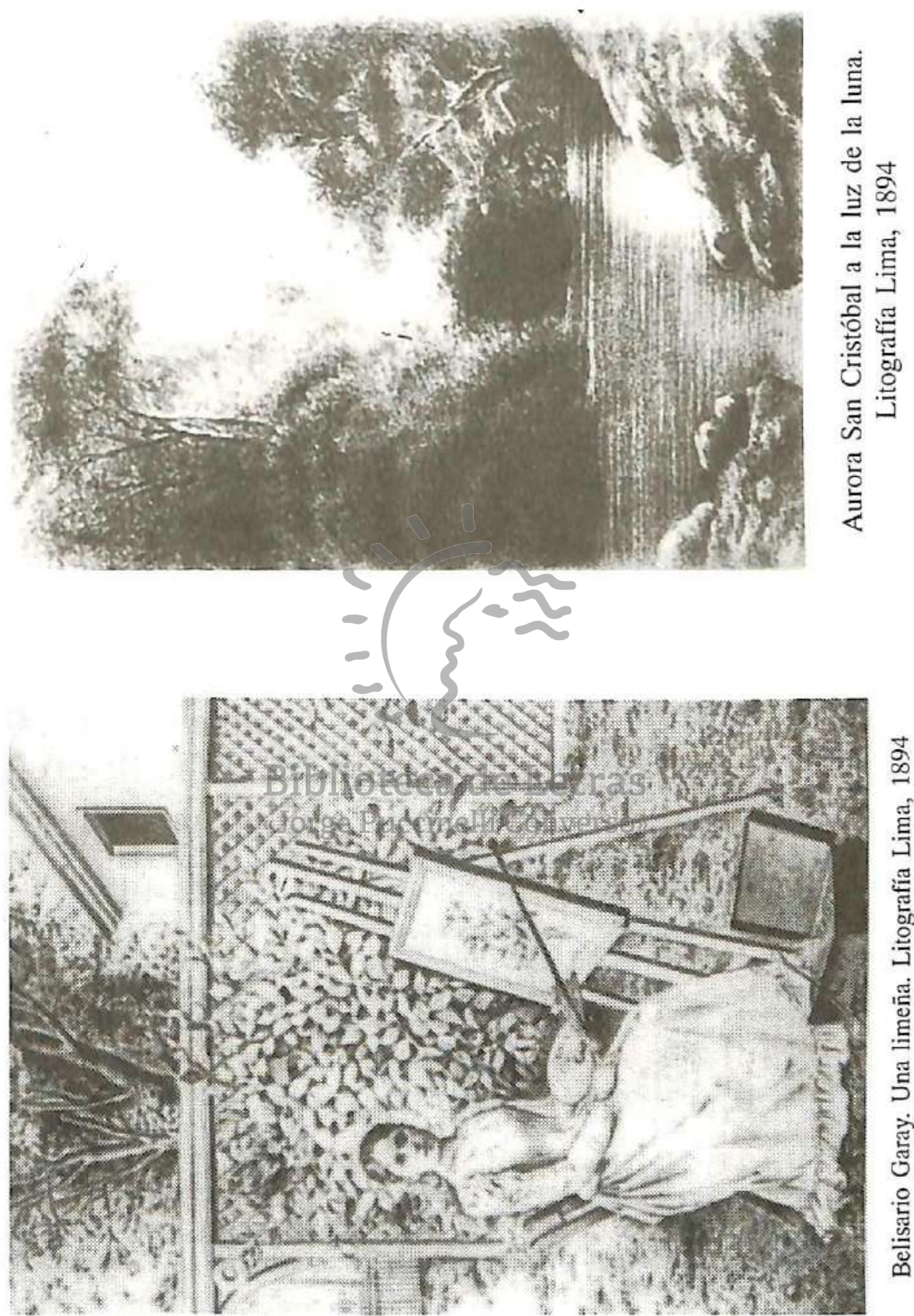




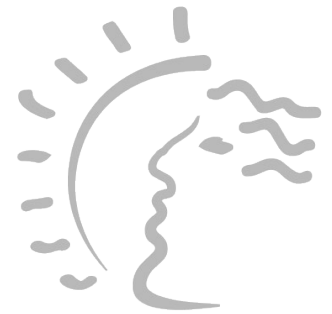

Biblioteca de Letras "Jorge Puccinelli Converso" 